\title{
O PAPEL DOS PROGRAMAS UNIVERSITÁRIOS DE INCENTIVO AO EMPREENDEDORISMO E INOVAÇÃO: UM ESTUDO DE CASO DO PROGRAMA EMPREENDA
}

Madhava Ferreira Gonçalves Gomes ${ }^{1}$ Tatiane Barleto Canizela Guimaraes ${ }^{1}$ Flavia Virginia Santos Teixeira Lana ${ }^{1}$

\footnotetext{
${ }^{1}$ Centro Universitário de Belo Horizonte
} 


\section{O PAPEL DOS PROGRAMAS UNIVERSITÁRIOS U DE INCENTIVO AO EMPREENDEDORISMO E INOVAÇÃO: UM ESTUDO DE CASO DO PROGRAMA EMPREENDA}

Resumo: Este estudo se propôs a analisar a atuação de um Centro Universitário de Belo Horizonte no processo de estimulo à educação empreendedora. Realizou-se uma pesquisa exploratória, qualitativa-quantitativa do tipo estudo de caso, com alunos de 13 diferentes cursos participantes de um programa da instituição. A partir da revisão teórica sobre educação empreendedora elaborou-se um questionário para aplicar junto aos alunos participantes. Verificou-se que há uma preocupação da instituição em disseminar a cultura empreendedora junto à comunidade acadêmica e local a partir de mecanismos como: formação de docentes, disciplinas de empreendedorismo, programas de desenvolvimento de projetos de negócios, palestras e centro de inovação voltado à pesquisa, desenvolvimento tecnológico e empreendedorismo com metodologia Fablabs. Conclui-se que o programa estudado atingiu seu objetivo de fomentar atividades de inovação e empreendedorismo no âmbito educacional, incentivando a comunidade acadêmica a engajar-se em ações inovadoras e que a instituição pesquisada pode ser considerada um "universidade empreendedora".

Palavras-chave: educação empreendedora, ensino superior, inovação, startup.

\section{Introdução}

Muito se tem falado a respeito do termo empreendedorismo tanto no âmbito empresarial quanto educacional. A desaceleração econômica vivida no Brasil desde 2014 e que culminou com um período recessivo nos mercados internacionais, mostrou-se menos favorável ao empreendedorismo por oportunidade e acarretou um incremento no empreendedorismo por necessidade. O lado negativo desse último, segundo dados do Sebrae (2016) é que $23 \%$ dessas empresas encerram suas atividades até o $2^{\circ}$ ano de vida e as principais razões para isso são a falta de preparação e a insuficiência de capital. Segundo dados do estudo realizado pelo Monitoramento Global de Empreendedorismo (GEM) a Taxa Total de Empreendedores (TTE) brasileiros em 2016, apresentou valor de 36,0\%, número inferior à observada em 2015 $(39,3 \%)$ e a Taxa de Empreendedorismo Inicial (TEA), composta por empreendedores nascentes e novos, alcançou o valor de 19,6\%, também inferior a 2015 (21,0\%) (GEM, 2016).

Destaca-se o fato que a TEE no Brasil ficou mais baixa para os indivíduos mais novos (entre 18 - 24 anos) e mais alta (acima de 20\%) para indivíduos com mais de 35 anos. Somada a idade ressalta-se o fato de no Brasil, os empreendedores com faixa de escolaridade "experiência pós-graduação" é a que apresentou maior índice de indivíduos engajados em novos empreendimentos (22,9\%). Essa representatividade abre possibilidade para abertura de negócios mais bem planejados e destaca a importância de programas de incentivo ao empreendedorismo e inovação no ensino superior, dado que empreendedores possuem mais conhecimentos técnicos, desenvolvidos ao longo da graduação e pós-graduação.

Comparando os resultados do GEM aos do Estudo Mundial sobre Empreendedorismo junto aos Estudantes Universitários (Global University Entrepreneurial Spirit Students' 
Survey - GUESSS) observa-se que o contexto universitário desempenha um papel muito importante na educação para o empreendedorismo e que o clima empreendedor é um determinante essencial das intenções e atividades empreendedoras (GUESSS, 2018). Entretanto, dos 54 países participantes do estudo apenas 20 a $25 \%$ dos alunos frequentaram cursos eletivos ou obrigatórios de empreendedorismo e somente $7,1 \%$ deles estudaram em um curso específico.

As bases conceituais da pesquisa GUESSS são baseadas na "teoria do comportamento planejado" de Ajzen, (2002), na qual o comportamento planejado é visto como determinado pela atitude (preferência ou evitação de um comportamento), normas subjetivas e senso de controle (capacidade percebida de auto-regular ou controlar as próprias ações). A utilidade dessa estrutura analítica para se estudar a intenção empreendedora dos estudantes e a educação superior em empreendedorismo foi confirmada por estudos empíricos tais como Fayolle, Gailly e Lassas-Clerc, (2006), Miller et al., (2009), Costa, Barros e Carvalho (2011), Lima et al., (2015), Schaefer e Minello, (2016), Salusse e Andreassi, (2016), Almeida, Cordeiro e Silva (2018), dentre outros.

Diante das questões que envolvem o desenvolvimento do ensino empreendedor, o presente estudo tem por objetivo analisar um dos programas de educação empreendedora de um Centro Universitário particular localizado na cidade de Belo Horizonte e avaliar a percepção dos alunos participantes do programa em relação ao potencial de desenvolvimento de seu comportamento empreendedor e em relação ao desenvolvimento dos projetos desenvolvidos por eles.

O estudo sobre o desenvolvimento do ecossistema empreendedor e do tema educação empreendedora é de fundamental importância e justifica-se pelo impacto desses no ecossistema de inovação. Apesar do crescente número de pesquisas e pelo amadurecimento do campo de estudo (COSTA; BARROS e CARVALHO, 2011; SONDARI, 2014) pesquisadores concordam que o tema "educação empreendedora no ensino superior" carece de maiores debates que auxiliem em seu amadurecimento e disseminação eficaz para formação de melhores empresários/empreendedores, gestores de inovação, além da geração de empregos e de riqueza no país (ROCHA e FREITAS, 2014; ALMEIDA, CORDEIRO e SILVA, 2018).

Este artigo subdivide-se em seis partes, sendo a primeira esta introdução, que apresenta o tema do trabalho, os objetivos e a justificativa. Ela é seguida do referencial teórico, que se subdivide quatro partes, que irá tratar sobre, empreendedor, empreendedorismo, conceitos de startups e o ensino de empreendedorismo, e da metodologia da pesquisa a ser realizada. $\mathrm{Na}$ sequência, descreve-se a organização onde o estudo se deu e apresentam-se a análise dos dados e as considerações finais. Ao final, estão expostos as referências.

\section{Referencial Teórico}

\subsection{Empreendedorismo e a expansão do campo.}

Apesar da falta de consenso, o campo do empreendedorismo expandiu e seus componentes múltiplos têm sido observados e analisados por economistas, sociólogos, historiadores, psicólogos, especialistas de ciências do comportamento ou de ciências da gestão segundo Filion (1997). 
O termo empreendedor, é usado na academia, no comércio, pela mídia e nas conversas informais por pessoas comuns há mais de dois séculos, mas questiona-se ainda hoje sobre um consenso ou unificação do campo (GUIMARÃES, 2004). Inicialmente o empreendedorismo foi identificado por economistas tais como Cantillon e Say, como um elemento útil à compreensão do desenvolvimento econômico como resultado da criação de novos empreendimentos (SAY, 1816 apud FILION, 1999). Os empreendedores eram vistos como pessoas que aproveitavam as oportunidades objetivando o lucro e assumindo um risco e portanto associados à inovação.

Apesar dos trabalhos anteriores foi Schumpeter (1942) quem iniciou os estudos sobre o o empreendedorismo, por meio de sua associação clara à inovação, interessado em compreender o papel do empreendedor como motor do sistema econômico, como detector de oportunidades de negócios, como criador de empreendimentos e como aquele que corre risco, como pode ser observada nessa passagem: “... sempre tem a ver com criar uma nova forma de uso dos recursos nacionais, em que eles sejam deslocados de seu emprego tradicional e sujeitos a novas combinações" (SCHUMPETER, 1942 apud Filion, 1999, p. 12).

Complementar a corrente econômica, os teóricos comportamentalistas, tentaram entender o empreendedor. Weber foi um dos primeiros autores a interessar-se pelo assunto, por volta de 1930, ao procurar identificar o sistema de valores dos empreendedores como elemento fundamental para a explicação de seus comportamentos. Apesar dos trabalhos de Weber, foram os de McClelland (1971) quem realmente contribuíram para o estudo do comportamento no ramo do empreendedorismo.

Foi McClelland quem identificou uma série de elementos, como a presença de heróis na literatura que eram tidos como modelos e que tinham seus comportamentos imitados. Sua definição de empreendedor era a seguinte: "alguém que exerce controle sobre uma produção que não seja só para o seu consumo pessoal (...) um executivo em uma unidade produtora de aço na União Soviética é um empreendedor”, (MCCLELLAND, 1971).

Para a linha comportamental são traçados os perfis de personalidade a partir do comportamento dos sujeitos empreendedores. Apesar de terem dominado o campo do empreendedorismo até o início dos anos 1980 foram alvos de várias criticas, sendo as principais relativas a sua simplicidade, por usar somente dois fatores principais: a necessidade de realização e a necessidade de poder (FILION, 1999). Numerosas pesquisas foram focadas nas características individuais e nos traços de personalidade dos empreendedores. Apesar de todas essas pesquisas, os resultados mostraram-se bastante contraditórios, mesmo que adotando metodologias adequadas e às vezes parecidas (GUIMARÃES, 2004).

Welsch (1992) destaca que a partir dos anos 1980 houve grande crescimento do campo e expansão por quase todas as ciências gerenciais e humanas, tendo sido identificado 27 temas dominantes no campo do empreendedorismo. Dentre esses temas, neste trabalho interessa-se pela temática da educação empreendedora no ensino superior.

\subsection{Educação empreendedora no ensino superior.}

Além dos estudos e impactos dos comportamentos empreendedores e seus impactos econômicos existem outros fatores fundamentais para a existência do ecossistema empreendedor. Aleisa, (2013) e Torres e Souza, (2016) dividem esses fatores em dois 
seguimentos: fatores tangíveis tais como as estações de trabalho, mentores, investidores, instituição de fomento à inovação e empreendedorismo, universidades, centros de pesquisa e parques tecnológicos; e fatores intangíveis que estão relacionados ao conhecimento e são responsáveis pelo início do processo de estruturação de negócios, tais como ideias, habilidades e atitudes empreendedoras.

Ramos e Ferreira (2004) já apontavam que o ensino de empreendedorismo no meio universitário era uma tendência. Em geral, os estudos na área de empreendedorismo, quando realizados em instituições de ensino, objetivam avaliar o quanto o ambiente acadêmico contribui para o desenvolvimento do perfil do empreendedor do egresso (SCHMIDT; BOHNENBERGER, 2008; FERREIRA e MATTOS, 2003). Atualmente, as universidades assumiram novos papéis, em busca de uma maior cooperação com empresas, órgãos de inovação e pesquisa do Governo e parcerias com incubadoras, parques, centros tecnológicos e demais espaços de inovação do ecossistema de inovação das cidades. Essas parcerias e programas, segundo Jansen et al. (2015), tornaram-se mais eficazes e eficientes por meio de práticas empreendedoras que visam estimular competências empreendedoras nos alunos e a criação de startups acadêmicas.

Esse dinamismo de programas de educação empreendedora em universidades, coloca as universidades como atores centrais na produção de conhecimento de base para a criação de novos negócios (RUBIN et al., 2015). O sucesso dos grandes pólos de inovação como por exemplo o do Vale do Silício (Califórnia) realizado em parceria direta com universidades também ajudam a explicar o grande interesse por práticas e pesquisas na área de educação empreendedora e universidade empreendedora.

Segundo Jansen et al. (2015) as universidades empreendedoras diferenciam-se por oferecer serviços ligados à educação (cursos de empreendedorismo), incubação (espaço físico, programas de aceleração e mentorias) e demais ações de estímulo (auxílio e infraestrutura para o desenvolvimento de protótipos, financiamento de equipes de alunos e de professores, prêmios e desafios, além de palestras e criação de canais de divulgação de oportunidades no ecossistema de empreendedorismo local.

Para Dornelas (2008), o processo empreendedor pode ser ensinado e entendido por todos. Já Dolabela (2008), afirma que ainda não existe uma conclusão científica no que diz respeito sobre a possibilidade de ensinar alguém a ser empreendedor, mas acredita-se que é possível aprender a ser um empreendedor e, para isso, é fundamental a criação de um ambiente que beneficie esse aprendizado. Lima, Santos e Dantas (2006) consideram a formação da personalidade empreendedora por meio da educação parte fundamental para o fomento da educação em empreendedorismo e, em consequência, para o desenvolvimento social.

De modo geral, as obras literárias sobre empreendedorismo têm oferecido um considerável suporte para o desenvolvimento de iniciativas de ensino, onde o desafio que se desdobra é a sua implementação na prática curricular das IES e a consequente avaliação dos resultados dessas iniciativas. (MARTENS; FREITAS, 2006)

Para que o empreendedorismo seja uma realidade na prática dos estudantes surge a necessidade de se criar programas de incentivo ao empreendedorismo em universidades. $\mathrm{O}$ modelo elaborado por Leydesdorff e Etzkowitz (1998) chamado tríplice hélice de inovação, aborda esse assunto, ao caracterizar a conexão entre diferentes estágios do processo de 
desenvolvimento e propagação do conhecimento, onde cada hélice - universidade, empresa e governo - classifica-se como uma área institucional independente, mas que trabalha em cooperação e interdependência com as demais áreas por meio de fluxos de conhecimento estimulando a inovação e a vantagem competitiva das empresas. Nesse modelo, o conceito de Universidade Empreendedora emerge como resposta às demandas da sociedade, apesar de todos desafios que esse modelo apresenta e que estão relacionados a adoção de metodologias que ofereçam um processo educacional que seja inovador, que estimule a criatividade e que ofereça mecanismos de gestão do risco relativos aos projetos de empreendedorismo.

O modelo da tríplice hélice, segundo Leydesdorff e Etzkowitz, (1998) gera uma infraestrutura de conhecimento de maneira a sobrepor os três atores (Governo, Academia e Empresa) oferecendo assim condições e um ambiente propício à inovação que culmina com o surgimento e fortalecimento das spin-offs acadêmicas respondendo as demandas da sociedade e em parceria entre laboratórios de pesquisa e agentes públicos e privados. As universidades passam a combinar seus recursos para além de ensinar, estimular e potencializar atividades de pesquisa com a missão de promover o desenvolvimento econômico e social a partir da disseminação da cultura empreendedora.

Ainda segundo Leydesdorff e Etzkowitz, (1998) esse modelo requer mudanças internas em cada uma das hélices, o reconhecimento da influência e da parceria com outros atores e instâncias tais como leis e órgãos de registros de patentes e propriedade intelectual, a criação de redes de cooperação com atores do ecossistema de inovação de maneira a estimular a criatividade e auxiliar no sucesso dos projetos criados internamente nas universidades.

No Brasil, o tema da educação empreendedora, no âmbito governamental é apoiado pela Organização das Nações Unidas para a Educação, a Ciência e a Cultura (UNESCO), em seu Projeto Regional de Educação para a América Latina e o Caribe -PRELAC que incluiu o pilar do "aprender a empreender" como um dos pilares de sustentação da política educacional, , atrelando-o à missão de gerar alternativas para o desemprego e como fonte de produção coletiva de riquezas e inovação. Esse pilar atua assim como um investimento nacional em longo prazo.

A necessidade de educar para o empreendedorismo, além da educação básica tradicional oferece a possibilidade de agregar aos alunos habilidades e competências requeridas e desejadas no mercado de trabalho atual (DOLABELA, 2003).

De acordo com Guerra e Grazziotin (2010), o papel das universidades na educação empreendedora é marcado pela seguinte afirmação "não se cria um empreendedor apenas numa sala de aula, mas é possível criar, em uma universidade crítica e criativa, profissionais com uma mentalidade empreendedora" (GUERRA e GRAZZIOTIN In LOPES, 2010, p.68).

\section{Metodologia}

Para responder à problemática proposta foi utilizada uma metodologia qualitativa e quantitativa, de natureza exploratória (GHAURI; GRONHAUG, 2005), utilizando um estudo de caso exploratório (YIN, 2002).

Nesta pesquisa, teve-se a oportunidade de estudar um programa de educação empreendedora realizado em um Centro Universitário particular localizado na cidade Belo Horizonte - MG de forma a explorar as contribuições do programa em relação ao desenvolvimento do perfil empreendedor dos alunos participantes assim como suas 
contribuições aos projetos desenvolvidos a partir da descrição das características de uma determinada população em uma experiência.

O programa de incentivo ao empreendedorismo estudado, por questões de sigiloso e de acordo com o código de ética será aqui denominado, Programa Empreenda, é realizado em um Centro Universitário localizado na cidade de Belo Horizonte, MG, em dois de seus campi.

A população do estudo é composta por 1.536 alunos da instituição pesquisada, que participaram do programa escolhido para o estudo, o critério de escolha da amostra foi não probabilística por acessibilidade, pois conforme Costa Neto (1977, p. 43) "nem sempre é possível se ter acesso a toda a população objeto de estudo, sendo assim é preciso dar segmento a pesquisa utilizando-se a parte da população que é acessível na ocasião da pesquisa".

Para reunir um material empírico do programa de educação empreendedora realizou-se, no período de 24 de junho a 10 de setembro de 2019, uma campanha da aplicação de questionário de avaliação por escala e contou com a participação de 126 alunos de 13 cursos participantes do Programa Empreenda edição 2019/1 do total de 1.536 alunos envolvidos em 18 cursos, o que representa $8,2 \%$.

O questionário composto por 16 questões de avaliação por escala, mais especificadamente a escala Likert, tem suas bases conceituais ancorados na pesquisa GUESSS baseadas na "teoria do comportamento planejado" de Ajzen, (2002), na qual o comportamento planejado é visto como determinado pela atitude, normas subjetivas e senso de controle. As questões buscaram avaliar a percepção dos alunos participantes do programa em relação ao programa e ao desenvolvimento de suas habilidades e competências pessoais e profissionais (técnicas) para empreender conforme figura 1 abaixo.

Figura 1- Fundamentos conceituais do Estudo GUESSS Brasil

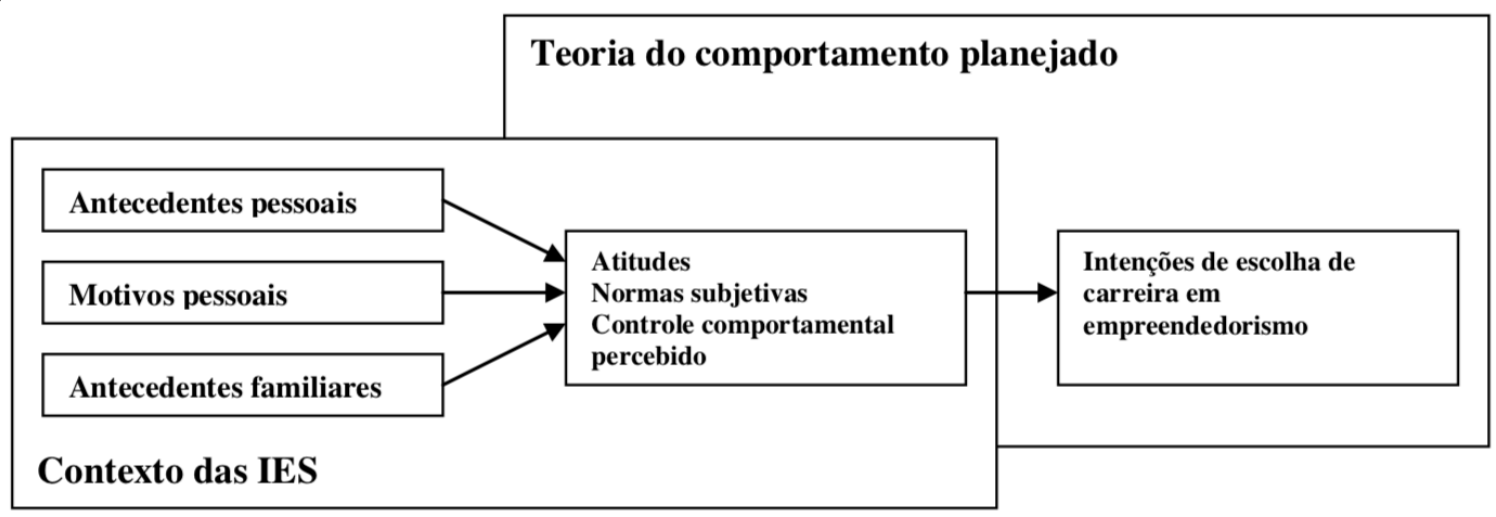

Fonte: Ajzen (2002) e Fishbein e Ajzen (1975).

Para aprimoramento da ferramenta escolhida para a coleta de dados, foi realizado um pré-teste, cujo objetivo foi validar o questionário e, de antemão, obter respostas em profundidade pelos participantes sobre os temas abordados na pesquisa.

A fim de obter o maior número de retorno possível, o questionário foi aplicado presencialmente durante o evento de encerramento do Programa Empreenda, utilizou-se também de uma plataforma online para o preenchimento do mesmo com link enviado por email pelos professores orientadores do projeto. 
Outros dados primários também foram obtidos a partir de observação não participante em eventos realizados ao longo do Programa Empreenda. A participação nesses eventos permitiu uma melhor compreensão do contexto da pesquisa, conhecimento das técnicas e práticas realizadas e uma familiarização e adaptação à "linguagem e rituais" do participantes. Como parte da observação não participante, durante os encontros físicos pode-se também observar e analisar a dinâmica de interação dos alunos e da equipe organizadora.

\section{Análise de dados}

O caso é estruturado de acordo com os três objetivos elencados previamente: analisar um programa de educação empreendedora, avaliar a percepção dos alunos participantes em relação ao potencial de desenvolvimento de seu comportamento empreendedor e finalmente a relação da participação do projeto com o desenvolvimento dos projetos desenvolvidos por eles.

\subsection{Análise da organização e do Programa de educação empreendedora em estudo}

O Centro universitário analisado tem mais de cinco décadas de existência e busca manter uma posição de investimento constante em metodologias inovadoras de ensino e tecnologia. Atualmente, oferece mais de 40 cursos de graduação, nas modalidades bacharelado, licenciatura e graduação tecnológica além de dezenas de cursos de pósgraduação lato sensu e projetos de extensão. De acordo com a coordenadora responsável pelo Programa Empreenda, a IE visa estimular "a praticidade, a criatividade e o esforço, sobretudo, na utilização de métodos que desenvolvem o pensamento crítico e inovador dos estudantes a partir do trabalho em equipe, estimulo a criatividade, aprendizagem com os erros, autonomia, liderança com fundamento e portanto tem o empreendedorismo como uma atitude". A partir das análises de documentos, observações e pesquisa de campo realizada a IE pode ser classificado como uma "Universidade empreendedora" (Jansen et al., 2015) por oferecer programas de formação empreendedora para seus docentes, treinamentos para equipe responsável, cursos de empreendedorismo para todos os seu alunos de todos os cursos, além de possuir programas de incubação e um coworking. Também disponibiliza ferramentas para auxílio à prototipagem de produtos e oferece programas e ações promotoras do empreendedorismo para sua comunidade acadêmica e para a população em geral.

O Programa Empreenda, analisado como um caso, é um programa com duração de 16 semanas cujo objetivo é fomentar atividades de inovação e empreendedorismo no âmbito educacional, incentivando a comunidade acadêmica a engajar-se em ações inovadoras, transformando as ideias desenvolvidas durante as aulas de diversas disciplinas em negócios reais e potenciais startups. Este processo é orientado por mentores e professores, no qual os alunos precisam montar um grupo e propor um projeto que atenda a um problema do seu campo de atuação.

\subsection{Perfil dos participantes.}

Após a tabulação de dados, observou-se que a população de gênero feminino foi superior ao masculino, sendo $65,1 \%$ dos respondentes mulheres e $34,9 \%$ homens. Com 
relação a idade dos respondentes $71,4 \%$ possuem até 25 anos, $26,2 \%$ entre 26 e 35 e apenas $2,4 \%$ possuíam mais de 36 e menos do que 65 anos.

O Programa Empreenda é oferecido para 13 cursos a saber: administração de empresas, biomedicina, ciência da computação, ciências contábeis, engenharia civil, engenharia química, engenharia de produção, engenharia ambiental, engenharia mecânica, engenharia elétrica, medicina, pedagogia e psicologia. Obteve-se resposta de todos os cursos participantes, contudo com diferentes graus de participação conforme figura 2 abaixo.

Figura 2 - Distribuição dos alunos por curso

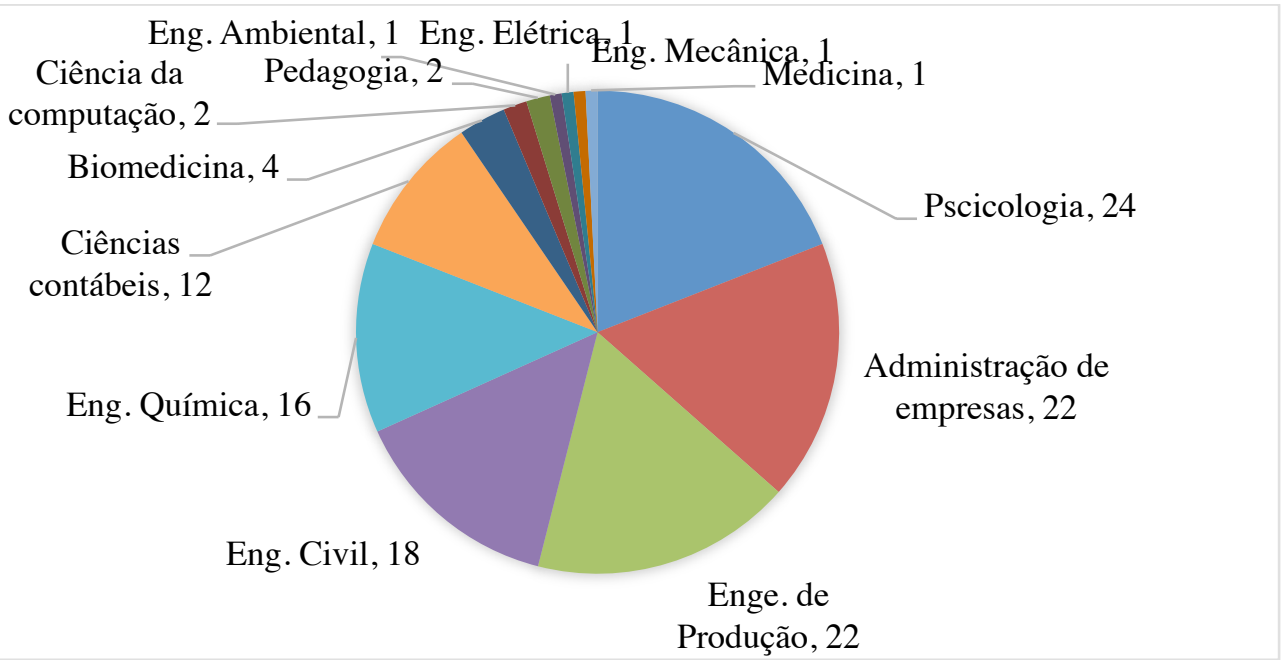

Fonte: dados da pesquisa, 2019.

\subsection{Avaliação dos participantes em relação ao seu comportamento e desenvolvimento de suas habilidades e competências.}

Questionados sobre o grau de conhecimento a respeito do conceito de empreendedorismo, observou-se que $42,1 \%$ dos respondentes afirmam ter um grau de conhecimento bom, $28,6 \%$ muito bom, 19,8\% razoável, 7,9\% excelente e apenas $1,6 \%$ ruim.

Ao analisar a opinião dos respondentes sobre a importância da abordagem de empreendedorismo oferecida pelo Programa Empreenda como uma disciplina em sua formação superior. Do total de respondentes, $75,4 \%$ deles afirmaram que o programa foi importante para sua formação, $22,2 \%$ concordam que a importância foi parcial, $0,8 \%$ discordam parcialmente da importância do programa para sua formação e 1,6\% afirmaram que o programa foi indiferente, corroborando assim com os autores Dornelas (2008) e Ramos e Ferreira (2004), que afirmam que o processo empreendedor pode ser ensinado e entendido e que o ensino de empreendedorismo no meio universitário é uma tendência.

Como é possível observar na figura 3 abaixo, a respeito da contribuição do Programa Empreenda para o desenvolvimento do perfil empreendedor dos alunos participantes, 39,7\% dos alunos afirmaram que o programa contribuiu parcialmente para o desenvolvimento de sua 
capacidade empreendedora, $38,1 \%$ dos alunos acreditam que o programa contribuiu plenamente, que o mesmo foi efetivo, contudo $15,1 \%$ dos alunos afirmaram que a participação no programa foi indiferente para o desenvolvimento de sua capacidade empreendedora, outros $4 \%$ afirmaram que o programa não contribuiu e para $3,2 \%$ o programa não contribuiu em nada para o desenvolvimento do seu perfil empreendedor.

Figura 3 - Avaliação do desenvolvimento da capacidade empreendedora dos alunos pela participação do Programa Empreenda.

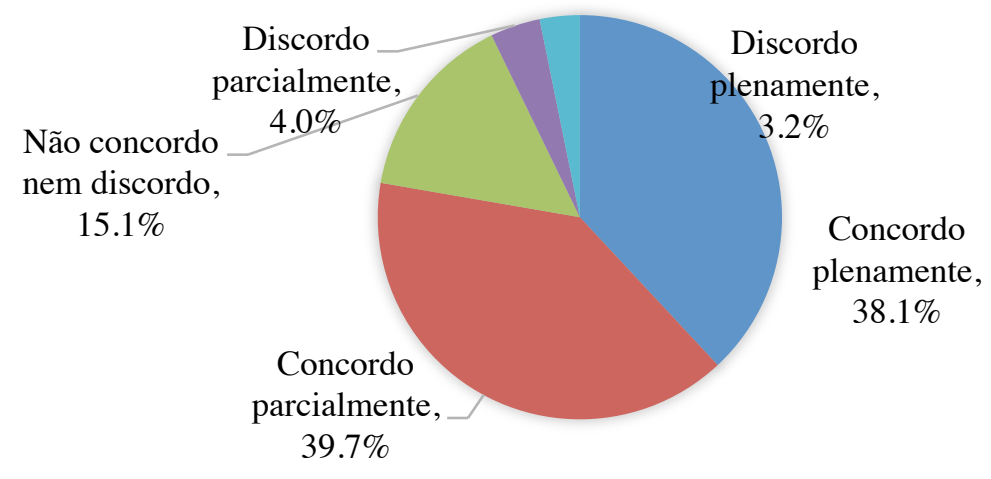

Fonte: dados da pesquisa, 2019.

De acordo com os dados da pesquisa, para 80\% dos respondentes Programa Empreenda contribuiu para o desenvolvimento da capacidade de liderança, sendo que para $37,6 \%$ dos a contribuição foi boa, para $26,4 \%$ a contribuição foi muito boa e para $15,2 \%$ a contribuição foi excelente. Entretanto para $20 \%$ o programa não contribuição, sendo que para $18,4 \%$ o programa contribuiu apenas de forma razoável e para 2,4\% o programa não contribuiu nada para o desenvolvimento de sua capacidade de liderança. De acordo com Ferreira et al. (2011) a capacidade de liderança é uma das características atuais mais importante para empreendedores, dessa forma observa-se que o Programa Empreenda tende a contribuir para a formação dos alunos participantes da formação.

Dolabela (2008) relaciona outros elementos que caracterizam os empreendedores, um deles é a criatividade, na questão sobre o grau de desenvoltura relacionado a mesma aproximadamente $80 \%$ da amostra afirmaram que o Programa Empreenda foi eficiente nesse aspecto, sendo que para $38,9 \%$ dos alunos respondentes o desenvolvimento/estímulo de sua criatividade foi bom, outros $29,4 \%$ afirmam que o desenvolvimento de sua criatividade foi muito bom e para $11,1 \%$ o desenvolvimento foi excelente. Por outro lado, $18,3 \%$ dos alunos afirmam que o desenvolvimento foi apenas razoável e outros $2,4 \%$ afirmaram que não houve nenhum desenvolvimento de sua capacidade de criatividade, conforme figura 4 abaixo. 
Figura 4- Grau de desenvolvimento da capacidade de criatividade dos alunos participantes do Programa Empreenda

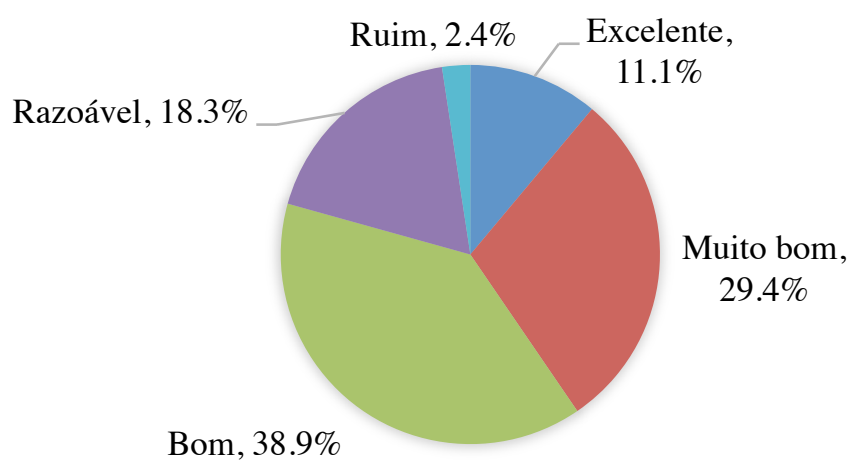

Fonte: dados da pesquisa 2019.

Indagados a respeito da contribuição do programa para que os integrantes dos grupos tivessem melhor desempenho referente a comunicação verbal, 35,7\% dos respondentes concordam que o programa desenvolveu plenamente sua capacidade de comunicação verbal, $33,3 \%$ afirmaram que a contribuição foi parcial. Por outro lado, $23 \%$ afirmaram que a participação no Programa Empreenda foi indiferente em relação ao desenvolvimento de sua capacidade e $4 \%$ discordam parcialmente e outros $4 \%$ discordam plenamente do poder do Programa X desenvolver essa competência. Conforme destacado por Kramer (2012) associado à melhoria da comunicação está a capacidade de estabelecer conexões, relações, com outros atores do ecossistema de inovação e empreendedorismo. Dessa forma, os alunos foram questionados sobre como o Programa contribuiu para aumento e/ou desenvolvimento de sua capacidade de realizar networking com outros atores. Do total de alunos respondentes, 35,7\% dos alunos afirmaram que o Programa Empreenda contribui plenamente, outros 31,7\% afirmaram que o desenvolvimento foi parcial. Entretanto, 8,7\% dos alunos respondentes discordaram da capacidade de desenvolvimento de sua capacidade de realizar networking, sendo que 5,6\% afirmaram que a contribuição foi apenas parcial e para, 18,3\% dos alunos respondentes a participação no Programa foi indiferente para o desenvolvimento dessa capacidade.

A pesquisa também buscou analisar a contribuição do Programa Empreenda para melhoria do produto ou serviço desenvolvido pelos alunos. Conforme ilustrado na figura 5 abaixo, para 33,3\% dos alunos respondentes o programa contribuiu plenamente neste sentido, para $31,7 \%$ a contribuição foi parcial. Por outro lado para 7,9\% dos alunos, o programa não contribuiu nada e para $4 \%$ dos alunos o programa contribui muito pouco para o desenvolvimento da melhoria dos ideias dos produtos ou serviços inicialmente idealizados por eles. Destaca-se que $23 \%$ dos alunos apresentaram neutralidade nessa pergunta. Segundo Guerra e Grazziotin (2010) o ensino de empreendedorismo em programas de educação superior contribui com as inovações e demandas do mundo moderno, dado que os alunos são instruídos a buscar a melhoria de seus produtos e serviços de forma atender as necessidades de seu público alvo. 
Figura 5 - Melhoria dos produtos e serviços desenvolvidos pelos alunos no Programa Empreenda.

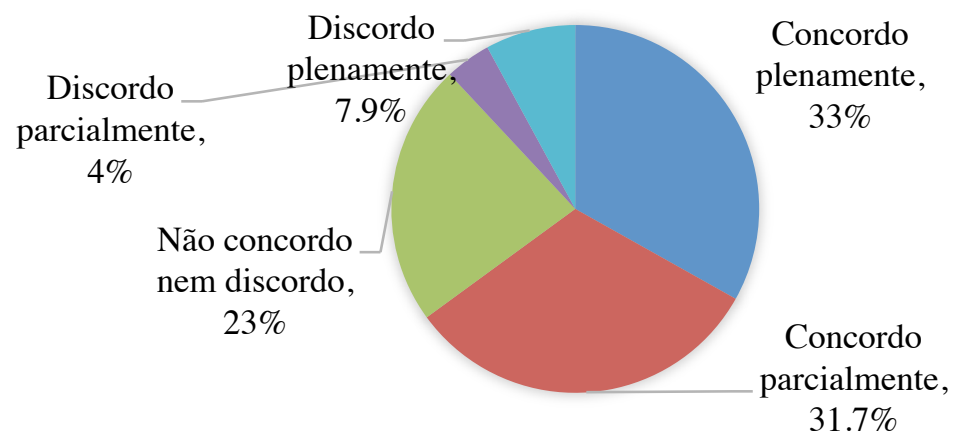

Fonte: dados da pesquisa, 2019.

Ao serem questionados sobre como a participação no programa contribuiu para a visibilidade do projeto desenvolvido por eles no ecossistema de Startups da cidade de Belo Horizonte, $32,5 \%$ dos alunos concordam plenamente que o programa contribuiu para que o projeto desenvolvido tivesse maior visibilidade no ecossistema de startups, $29,4 \%$ concordam parcialmente, 24,6\% afirmaram que a participação foi indiferente. Por outro lado 7,1\% dos alunos discordaram parcialmente da capacidade do Programa Empreenda aumentar a visibilidade de seus projetos e $6,3 \%$ discordam plenamente.

Os alunos também foram questionados sobre a intenção de continuar a desenvolver os projetos que iniciaram a partir da participação do Programa X. Conforme observa-se pela figura 6 abaixo, 50,8\% dos respondentes afirmam ter intenção de levar o projeto desenvolvido no programa para o ecossistema empreendedor de startups (Mercado real), em contrapartida $33 \%$ não tem essa mesma intenção, e $26,2 \%$ ainda não tomaram esta decisão.

Figura 6 - Intenção dos alunos de desenvolverem o projeto desenvolvido ao longo do Programa Empreenda.

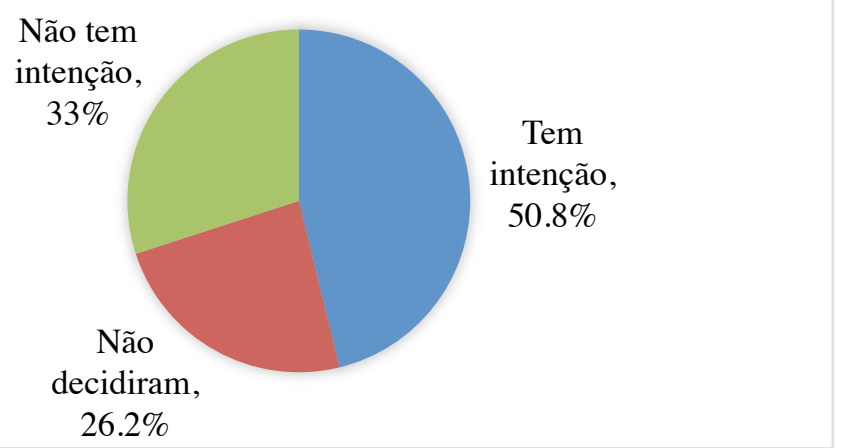

Fonte: dados da pesquisa, 2019.

De acordo com Corfo (2016) iniciativas que fomentam estes modelos de negócio são estratégias no cenário de incentivo do desenvolvimento de regiões ainda limitadas aos 
modelos econômicos convencionais, ou seja, as startups demostram ser relevantes para o desenvolvimento econômico e social do país, e para que tenham condições de competir em nível mundial, torna-se necessária a construção de um ecossistema favorável para o desenvolvimento dessas empresas.

\section{Considerações finais}

Diante do objetivo de identificar e analisar as melhorias e contribuições de um programa de educação empreendedora de ensino superior em relação ao perfil empreendedor dos alunos e aos projetos desenvolvidos, a pesquisa analisou um programa realizado em 13 cursos de um Centro Universitário localizado na cidade de Belo Horizonte - MG.

Com base nas informações analisadas, observou-se que de fato a participação dos alunos no Programa Empreenda desenvolve e intensifica o perfil empreendedor dos alunos participantes, dado que os alunos afirmaram que a partir das atividades realizadas ao longo do programa as características atuais dos empreendedores como a criatividade, capacidade de planejamento, comunicação verbal e liderança foram atenuadas e cultivadas o que vem de encontro com os dados relatório do Estudo GUESSS Brasil de 2011 e dos estudos de Hashimoto (2013) que buscaram traçar o histórico da educação em empreendedorismo nas IES brasileiras. A IE analisada reforça e dissemina o debate teórico debates e contribui para o amadurecimento desse campo de estudo (ROCHA e FREITAS, 2014; ALMEIDA, CORDEIRO e SILVA, 2018) ao fomentar a educação empreendedora a partir da realização de várias ações tais como palestras, oficinas, visitas técnicas, cursos e desafios empreendedores ampliando assim a rede de relação dos interessados em empreendedorismo no ensino superior.

A iniciativa da IE de buscar capacitar seus professores, criar uma cultura empreendedora e promover e estimular programas como o Empreenda que visa estimular a mentalidade empreendedora e a formação de startups por alunos de diferentes cursos representa um exemplo de Universidade Empreendedora que adquire um novo repertório pedagógico visando impulsionar e disseminar a formação de profissionais com perfil crítico, inovador e empreendedor, capazes de contribuir para a geração de empregos e de riqueza a partir da inovação. (GUERRA e GRAZZIOTIN, 2010)

Em relação a contribuição do Programa Empreenda analisado em relação aos projetos desenvolvidos pelos alunos, o programa também mostrou-se efetivo pois de acordo com os alunos as ferramentas utilizadas, possibilitaram melhora nos projetos e serviços desenvolvidos, além de proporcionar maior visibilidade dos projetos no ecossistema empreendedor, como consequência impulsionou o crescimento do ecossistema de startups de Belo Horizonte.

Diante disso, pôde-se identificar que o programa estudado atingiu seu objetivo de fomentar atividades de inovação e empreendedorismo no âmbito educacional, incentivando a comunidade acadêmica a engajar-se em ações inovadoras. A possibilidade de repensar a educação a partir de uma plataforma que seja capaz de transformar a educação e promover a educação empreendedora, como estratégia de promoção do desenvolvimento sócio-econômico e de promoção da inovação e da pesquisa aplicada está centrada em um modelo que estimula a criação de alunos protagonistas quem busquem aprender a aprender está centrado no modelo de Tríplice Hélice, ao integrar instituições de ensino de ensino, empresas e Governo (LEYDESDORFF; ETZKOWITZ, 1998). 
As conclusões apresentadas no estudo contribuem para o avanço da compreensão do fenômeno do ensino do empreendedorismo e disseminação dos conceitos sobre os temas abordados. Trabalhos futuros poderão ser aplicados novamente ao longo do desenvolvimento do Programa X de maneira a confirmar os dados obtidos neste estudo e comparados com dados de outros programas de educação empreendedora de forma a exercer comparações e identificar melhorias metodológicas a serem aplicadas.

\section{Referências}

ALEISA, Eisa. Startup Ecosystems: Study os the ecosystems around the world; Focusing on Silicon Valley, Toronto and Moscow, 2013.

BARRETO, L. P. Educação para o empreendedorismo. Educação Brasileira, 20(41), pp. 189-197, 1998.

CORFO. Corporación de Fomento de la Producción. Libro de casos de innovación CORFO. 2016.

COSTA NETO, P. L. O. Estatística. São Paulo: Edgard Blücher, 1977. 264 p.

COSTA, A. M. da.; BARROS, D. F.; CARVALHO, J. L. F. A dimensão histórica dos discursos acerca do empreendedor e do empreendedorismo. Revista de Administração Contemporânea, v. 15, n. 2, p. 179- 197, mar./abr. 2011.

DE ALMEIDA, Lucas Rodrigo Santos; CORDEIRO, Eugênia de Paula Benício; DA SILVA, Josebede Angélica Guilherme. Proposições acerca do Ensino de Empreendedorismo nas Instituições de Ensino Superior Brasileiras: uma Revisão Bibliográfica. Revista de Ciências da Administração, v. 1, n. 3, p. 109-122, 2018.

DE CARVALHO ROCHA, Estevão Lima; FREITAS, Ana Augusta Ferreira. Avaliação do ensino de empreendedorismo entre estudantes universitários por meio do perfil empreendedor. Revista de Administração contemporânea, v. 18, n. 4, p. 465-486, 2014.

DOLABELA, F. Oficina do empreendedor. Rio de Janeiro: Sextante, 2008.

DORNELAS, J. C. A. Empreendedorismo: transformando ideias em negócios. 3. ed. Rio de Janeiro: Elsevier, 2008

FAYOLLE, Alain; GAILLY, Benoit; LASSAS-CLERC, Narjisse. Assessing the impact of entrepreneurship education programmes: a new methodology. Journal of European industrial training, v. 30, n. 9, p. 701-720, 2006.

FERREIRA et al. Desde os primórdios até hoje em dia: será que o empreendedor ainda faz o que Schumpeter dizia? Evolução das características empreendedoras de 1983 a 2010. In: ENCONTRO DA ASSOCIAÇÃO NACIONAL DE PÓSGRADUAÇÃO E PESQUISA EM ADMINISTRAÇÃO, 35., 2011, Rio de Janeiro. Anais... Rio de Janeiro: Anpad, 2011

FERREIRA, M. P. V.; PINTO, C. F.; MIRANDA, R. M. Três décadas de pesquisa em empreendedorismo: uma revisão dos principais periódicos internacionais de empreendedorismo. Revista Eletrônica de Administração, v. 81, n. 2, p. 406-436, maio/ago. 2015.

FILION, Louis Jacques. Empreendedorismo: empreendedores e proprietáriosgerentes de pequenos negócios. Revista de Administração da Usp, São Paulo, v.34, n.2, abr./jun. 1999. p.5-28. 
GLOBAL ENTREPRENEURSHIP MONITOR. Empreendedorismo no Brasil. 2015. Disponível

em:<https://bibliotecas.sebrae.com.br/chronus/ARQUIVOS_CHRONUS/bds/bds.nsf/c6 de907fe0574c8ccb36328e24b2412e/\$File/5904.pdf.> Acesso em: Acesso em 10 de março 2019.

GUERRA, M. J.; GRAZZIOTIN, Z. J. Educação empreendedora nas universidades brasileiras. In: LOPES, R. M. A. (Org.). Educação empreendedora: conceitos, modelos e práticas. Rio de Janeiro: Elsevier: São Paulo: SEBRAE, 2010.

GUERRERO, M. ; URBANO, D. The development of an entrepreneurial university. The Journal of Technology Transfer, 37(1), p.43-74, 2012.

GUIMARÃES, Tatiane Barleto Canizela. Análise epistemológica do campo do empreendedorismo. XXVIII ENANPAD, 2004.

HENRIQUE, D. C.; CUNHA, S. K. Práticas didático-pedagógicas no ensino de empreendedorismo em cursos de graduação e pós-graduação nacionais e internacionais. Revista de Administração Mackenzie, v. 9, n. 5, p. 112-136, 2008.

HISRICH et al. Empreendorismo. Bookman, 7a. edição. Porto Alegre. 2014

HOLIENKA, M. Entrepreneurial Environment in Slovakia: Multi-Perspective Comparison with Innovation-Driven Economies. Procedia Economics and Finance, v. 34, p. 437-444, 2015.

IRINA, G.; ALINA, K. An Evaluation of Entrepreneurial Potential in the Republic of Tatarstan. Procedia Economics and Finance. V. 32, p. 345-351, 2015.

JANSEN, Slinger; VAN DE ZANDE, Tommy; BRINKKEMPER, Sjaak; STAM, Erik; VARMA, Vasudeva. How education, stimulation, and incubation encourage student entrepreneurship: Observation from MIT, IIIT, and Utretchr University. The International Journal of Management Education, v.13, n.2, p.170-181, 2015.

KRAMER. 101 Estratégias bem-sucedidas de Networking. Cengage Learning, a $^{\text {a }}$ Edição.2012.

LEYDESDORFF, L.; ETZKOWITZ, H. The Triple Helix as a model for innovation studies. Science and Public Policy, 25 (3), p. 195-203, 1998.

LIKERT, R. A technique for the measurement of attitudes. Archives in Psychology, 140, p. 1- 55, 1932.

LIMA, M. O; SANTOS, S. A; DANTAS, A. B. Propensão ao Empreendedorismo dos Alunos do Ensino Fundamental: um Estudo Comparativo com alunos de $7^{\mathrm{a}}$ e $8^{\mathrm{a}}$ séries, entre Instituições de Ensino Municipais e Privadas de Maceió. Salvador: ANPAD, 2006.

LYNN, H. D.; RADOJEVICH-KELLEY, N.; Analysis of accelerator companies: An exploratory case study of their programs, processes, and early results. Small Business Institute Journal, v. 8, n. 2, p. 54-70, 2012.

MARTENS, C. D. P; FREITAS, H. A Influência do Ensino de Empreendedorismo nas Intenções de Direcionamento Profissional dos Estudantes de Curso Superior: uma Avaliação a partir da Percepção dos Alunos. Gramado: ANPAD, 2006.

MCCLELLAND, D. C. A sociedade competitiva: realização e progresso social. Rio de Janeiro: Expressão e Cultura, 1972. 
MILLER, Brian K. et al. Predictors of entrepreneurial intentions: a quasi-experiment comparing students enrolled in introductory management and entrepreneurship classes. Journal of Business \& Entrepreneurship, v. 21, n. 2, 2009.

PAUWELS, Charlotte; CLARYSSE Bart; WRIGHT, Mike; VAN HOVE, Jonas. Understanding a new generation incubation model: The accelerator. Technovation. V. 50-51, p.13-24, 2016.

RAMOS, S. C.; FERREIRA, J. M. Levantamento das Práticas e Conteúdos do Ensino de Empreendedorismo nos Cursos de Graduação em Administração na Cidade de Curitiba - PR. Curitiba: ANPAD, 2004.

ROCHA, E. L. de C.; FREITAS, A. A. F. Avaliação do ensino do empreendedorismo entre estudantes universitários por meio do perfil empreendedor. Revista de Administração Contemporânea, v. 18, n. 4, p. 465-486, jul./ago. 2014.

SALUSSE, M. A. Y.; ANDREASSI, T. O ensino de empreendedorismo com fundamento na Teoria Effectuation. Revista de Administração Contemporânea, v. 20, n.3, p. 305-327, maio/jun. 2016.

SEIXAS, Marcus. Qual a melhor modalidade de investimento para o meu negócio?. Blog Susart \& Seixas - Advocacia 2018. Disponível em: < http://3s.adv.br/blog/qualmelhor-modalidade-de-investimento-para-o-meu-negocio/>. Acesso em 10 de março 2019.

SONDARI, M. S. Is Entrepreneurship Education Really Needed ? : Examining the Antecedent of Entrepreneurial Career Intention. Procedia - Social and Behavioral Sciences 115, $44-53,2014$.

VOICU-DOROBANȚU, R. European Regions and Entrepreneurial Ecosystems in the Context of the New Sustainable Development Goals. Journal of Eastern Europe Research in Business and Economics, Vol. 2016. 2016 